\title{
CULTURAS URBANAS E RESISTENCIA DA JUVENTUDE NEGRA: RESSONÂNCIAS DO TAMBOR NAS ESCOLAS DE PERIFERIA DE SÃO PAULO
}

\author{
CULTURAS URBANAS Y RESISTENCIA DE LA JUVENTUD NEGRA: RESONANCIA \\ DEL TAMBOR EN LAS ESCUELAS DE PERIFERIA DE SÃO PAULO
}

\section{URBAN CULTURES AND RESITANCE OF BLACK YOUTH: DRUM RESONANCES IN THE PERIPHERAL SCHOOLS OF SÃO PAULO}

\author{
Mônica Guimarães Teixeira do AMARAL ${ }^{1}$ \\ Cristiane Correia DIAS ${ }^{2}$ \\ Maria Teresa LODUCA ${ }^{3}$
}

RESUMO: Com uma preocupação voltada para a construção de novas práticas educacionais com base em uma epistemologia do sul, esta pesquisa propôs-se a realizar docências compartilhadas entre professores (as), artistas populares e pesquisadores (as), de modo a proporcionar outras perspectivas de atuação em sala de aula, com a introdução de práticas e saberes dos afrodescendentes nos conteúdos a serem abordados na escola. Neste artigo, abordaremos alguns momentos da docência compartilhada, denominada Hiphopnagô, promovida por duas pesquisadoras, das áreas de música e de dança breaking, com uma professora da Língua Portuguesa do ensino fundamental de uma escola pública de São Paulo. Com ênfase nos elementos musicais e de dança contemporâneos, procurou-se contemplar o contexto sócio histórico no qual se inserem as culturas cultivadas especialmente pela juventude afrodescendente. Pretende-se, desse modo, pensar em novas estratégias de ensino, assim como sobre os fundamentos de uma epistemologia do Sul brasileira afrocentrada.

PALAVRAS-CHAVE: Epistemologia do sul. Cultura afro-brasileira. Hip-hop e educação.

RESUMEN: Con una preocupación volcada hacia la construcción de nuevas prácticas educativas con base en una epistemología del Sur, esta investigación se propuso realizar docencias compartidas entre profesores (as), artistas populares e investigadores (as), para proporcionar otras perspectivas de actuación en el aula, con la introducción de prácticas y saberes de los afrodescendientes en los contenidos a ser abordados en la escuela. En este artículo, hemos compartido unos momentos de enseñanza, llamados Hiphopnagô, promovido por dos investigadores, en los campos de la música y la danza breaking con un profesor de Lengua Portuguesa en la educación primaria en una escuela pública de Sao Paulo. Con énfasis en los elementos musicales y de danza contemporáneos, se procuró contemplar el contexto socio-histórico en el que se insertan las culturas cultivadas especialmente por la juventud

\footnotetext{
${ }^{1}$ Universidade de São Paulo (USP), São Paulo - SP - Brasil. Departamento de Filosofia da Educação e Ciências da Educação. Livre-Docente. ORCID: <http://orcid.org/0000-0001-6951-5094>. E-mail: monicagta@homtail.com

${ }^{2}$ Universidade de São Paulo (USP), São Paulo - SP - Brasil. Departamento de Filosofia da Educação e Ciências da Educação. ORCID: <http://orcid.org/0000-0003-1036-2104>. E-mail: slc.cris@ hotmail.com

${ }^{3}$ Universidade de São Paulo (USP), São Paulo - SP - Brasil. Departamento de Filosofia da Educação e Ciências da Educação. ORCID: <http://orcid.org/0000-0003-4359-5588>. E-mail: tecatrompa@gmail.com
} 
afrodescendiente. Se pretende, de ese modo, pensar en nuevas estrategias de enseñanza, así como sobre los fundamentos de una epistemología del Sur brasileña afrocentrada.

PALABRAS CLAVE: Epistemología meridional. Cultura afro-brasileña. Hip-hop y educación.

ABSTRACT: Focusing on the construction of new educational practices based on a Southern epistemology, this research developed co-teaching experiences among teachers, popular artists and researchers, in order to provide other perspectives of action in the classroom, with the introduction of practices and knowledge from Afro-descendants in the contents to be addressed in the school. The current article focuses on some moments of a co-teaching experience, named Hiphopnago, promoted by two researchers, from music and dance breaking areas, with a Portuguese Language teacher in an elementary public school in São Paulo. With emphasis on the contemporary musical and dance elements, it sought to contemplate the socio-historical context in which the cultures were cultivated especially by the Afrodescendant youth. It is intended, therefore, to think of new teaching strategies, as well as on the foundations of an Afrocentric South Brazilian epistemology.

KEYWORDS: Southern epistemology. Afro - Brazilian culture. Hip - hop and education.

\section{Introdução}

A experiência de pesquisa aqui relatada faz parte de um projeto de pesquisa de políticas públicas, sob o título $\mathbf{O}$ ancestral e o contemporâneo nas escolas: reconhecimento e afirmação de histórias e culturas afro-brasileiras ${ }^{4}$, cujo objetivo foi colaborar para a implementação da Lei 10.639/03, que torna obrigatória a inclusão da história da África e das culturas afro-brasileiras no currículo das escolas públicas e privadas de educação básica. O delineamento do conjunto do trabalho de campo se deu tomando em consideração a diversidade étnica e cultural presente nas escolas brasileiras e tendo como base a experiência de colaboração interdisciplinar desenvolvida nos últimos dez anos, em torno dos elementos do hip-hop e das culturais ancestrais cultivadas pelos jovens nas periferias das metrópoles. Entre 2015 e 2018, esta pesquisa foi realizada em duas escolas municipais situadas em diferentes regiões periféricas da cidade de São Paulo, envolvendo docências compartilhadas entre artistas populares (da capoeira, do maculelê, do teatro negro, do hip-hop, dentre outros), pesquisadores (as) da universidade e professores (as) da rede municipal de ensino fundamental. Estas experiências de

${ }^{4}$ Pesquisa de políticas públicas: $\mathbf{O}$ ancestral e o contemporâneo nas escolas: reconhecimento e afirmação de histórias e culturas afro-brasileiras (Processo FAPESP/2015: 50120-8), coordenado pela Profa Dra Mônica do Amaral na Faculdade de Educação da Universidade de São Paulo-SP (FEUSP). 
docência compartilhada propiciaram a construção de um conhecimento em sala de aula que contemplassem os saberes e estéticas de matriz africana e seus hibridismos diaspóricos, como sugere Paul Gilroy (2001).

Nesse sentido, propusemo-nos a colaborar para a de(s)colonização do currículo, além de provocar tensões no interior da própria transmissão do saber técnico-científico veiculado pelas disciplinas escolares, além de criar novas estratégias didáticas para o ensino de história, literatura, geografia, inglês, português, educação física, entre outras disciplinas, por meio da música, da poesia, da dança e de lutas ancestrais e contemporâneas. Ao mesmo tempo, a ideia era superar hierarquias de saberes e conhecimentos, pela via do reconhecimento das contribuições das culturas que foram renegadas ou distorcidas pelo saber acadêmico, marcadamente monocultural e eurocêntrico. Ao propor um processo de ensino/aprendizagem aberto à diferença por meio do encontro com a ancestralidade de matriz africana, pretendíamos oferecer condições em sala de aula para a (res)significação das relações de afeto, de gênero e de raça.

Nossas experiências de pesquisa ${ }^{5}$ em escolas públicas de diferentes regiões periféricas da cidade de São Paulo demonstraram-nos o impacto do racismo institucional nas práticas docentes e cultura escolar. Um racismo que silencia as culturas de nossos afrodescendentes e impede, muitas vezes, que esses alunos se vinculem ao conhecimento, o que tem resultado em sérios prejuízos à formação desses jovens. Em contrapartida, foi possível identificar no instrumento africano - o tambor - considerado por nós, como um verdadeiro "cronótopo" da microcultura escolar, da qual fazem parte, os rituais e rotinas escolares e subjacente a estes, as culturas e ritmos de diferentes matizes africanos, por meio dos quais, foi possível reascender na memória dos afrodescendentes o desejo de se reconectar com suas experiências ancestrais. E, desse modo, provocar rupturas de campo ${ }^{6}$ no discurso e práticas hegemônicas, demonstrando aos educadores(as) e pesquisadores(as) como se pode provocar uma verdadeira "reversão

${ }^{5}$ Referimo-nos aos projetos de pesquisa de melhoria do ensino público e de políticas públicas desenvolvidas nos últimos dez anos, intituladas: Culturas juvenis x cultura escolar: como repensar as noções de tradição $e$ autoridade no âmbito da educação (2006-2009), Rappers, os novos mensageiros urbanos da diáspora afrobrasileira na periferia de São Paulo: a contestação estético-musical que emancipa e educa (2010-2014) e O ancestral e o contemporâneo nas escolas: reconhecimento e afirmação de histórias e culturas afro-brasileira, coordenados pelo autor (2015-2018). Todos contaram com financiamento da FAPESP (Fundação de Amparo à Pesquisa do Estado de São Paulo).

${ }^{6}$ Noção empregada pelo psicanalista Fábio Herrmann (2001) para se referir a um processo imanente ao ato interpretativo, que, segundo o autor, estaria associado a um estado de irrepresentabilidade transitória, como condição do surgimento de novas representações que dariam corpo à "prototeoria" do sujeito. No caso desta pesquisa, a prototeoria emergiu a partir das lembranças eliciadas pelo tambor, ou mais especificamente pelo atabaque, nos sujeitos negros em sala de aula, o que conferiu um redirecionamento à pesquisa. 
dialética"7 em sala de aula a partir dos próprios elementos estéticos renegados ou pouco utilizados no espaço escolar.

Este artigo foi construído com base em um recorte de uma das docências compartilhadas, denominada Hiphopnagô, promovida por duas pesquisadoras, das áreas de música $^{8}$ e de dança breaking ${ }^{9}$, com uma professora da Língua Portuguesa do ensino fundamental de uma escola pública de São Paulo. Esta experiência de docência compartilhada trouxe momentos preciosos de emergência do que designamos como afromemória. Uma memória que foi reativada entre os alunos afrodescendentes ao toque do tambor e da dança no ritmo do break beat. Essenciais para provocar rupturas de campo - do inconsciente individual e coletivo - no ambiente escolar, que tendia a negar tais experiências.

Com um olhar voltado para as tendências contemporâneas da cultura hip-hop e de como estas se mesclam com nossa ancestralidade, e de outro, para a especificidade daquela escola pesquisada, procuramos delinear uma metodologia, não de acordo com uma abordagem quantitativa, mas segundo uma abordagem qualitativa inspirada no método psicanalítico, que por sua vez, teria que ser repensado à luz dos fenômenos estudados. Procuramos ficar atentos para o próprio método construído pelos artistas do hip-hop, cuja pedagogia envolve um ir e vir entre elementos da cultura do passado e do presente, propiciando uma verdadeira "telescopia histórica" ${ }^{10}$ dos fenômenos contemporâneos, ou seja, uma leitura do presente com uma lente que ressignifica os elementos distantes no tempo histórico.

O objetivo deste trabalho conjunto, sobre o qual nos debruçamos no presente artigo, é contribuir para se repensar as práticas docentes e a cultura escolar hegemônica com base em uma epistemologia do Sul, atenta às especificidades das culturas afro-brasileiras. Com ênfase nos elementos musicais e de dança contemporâneos, procurou-se contemplar o contexto sócio histórico no qual se inserem as culturas cultivadas especialmente pela juventude afrodescendente.

\footnotetext{
${ }^{7}$ Reportamo-nos ao termo empregado por Gatti (2009), para se referir ao traço fundamental do pensamento de Walter Benjamin $(1936,1980)$ sobre a arte de massa, que aponta para uma espécie de "dialética de distanciamento e aproximação", de acordo com a qual o "pensamento aproxima-se mimeticamente de seu objeto de crítica, assimilando-se perigosamente a ele, até o ponto de sucumbir à sua força regressiva, como se essa fosse a única estratégia ainda disponível para sustentar um mínimo de distância crítica capaz de salvar suas potencialidades salvadoras" (GATTI, 2009, p. 299). No caso, referimo-nos ao uso do termo macumba para se referir ao tambor, se não estaria permeado por essa dialética de distanciamento e aproximação.

${ }^{8}$ Maria Teresa Loduca, cuja experiência faz parte de sua Dissertação de Mestrado, sob o título Música negra na escola: um estudo sobre a ressonância dos tambores nas relações intersubjetivas (Mestrado em Educação, FEUSP, 2018).

${ }^{9}$ Cristiane Correia Dias, cuja experiência faz parte de sua Dissertação de Mestrado, sob o título Por uma pedagogia hip-hop: o uso da linguagem do corpo e do movimento para a construção da identidade negra e periférica (Mestrado em Educação, FEUSP, 2018).

${ }^{10}$ Termo utilizado por: BÉTHUNE, C. Le rap: une esthétique hors la loi. Paris: Autrement, 2003.
} 
Passemos ao relato de alguns desses momentos. Em seguida, apresentamos uma reflexão acerca da importância de se retomar o diálogo entre a ancestralidade desses povos, historicamente prejudicados, como bem denominou o filósofo Axel Honneth (2003) e as culturas jovens urbanas na escola, como forma de construir um conhecimento engajado e culturalmente relevante para os nossos alunos.

\section{"Pandeiro? Onde eu aprendi a tocar? Eu sou preto, professora!" \\ "Se eu sei tocar atabaque? Foi meu pai antigo quem me ensinou!'}

Estas duas respostas foram dadas, em momentos distintos de nossa pesquisa ${ }^{11}$, à observação feita pela pesquisadora musicista a dois alunos de escolas públicas de São Paulo ${ }^{12}$ sobre como tocavam bem os ritmos propostos, fosse do samba, fosse do funk. No primeiro caso, tratava-se da habilidade do garoto em tocar o pandeiro, que, para ele era evidente, como se fosse algo inerente a ser negro. Já no segundo, a resposta não nos pareceu tão inequívoca, uma vez que remetia, não apenas às experiências do jovem nas rodas de samba com seu pai que se foi (a mãe casara-se pela segunda vez e ele perdera o contato com o pai). Parecia também se referir a uma ancestralidade retomada ao batucar no tambor afro-brasileiro - o atabaque.

A partir destas e de outras situações vivenciadas em sala de aula, descortinou-se toda uma história negada para as pesquisadoras e professora nas docências compartilhadas realizadas entre artistas/pesquisadoras (es) e professoras (es) do ensino fundamental.

As batidas dos tambores fizeram emergir os sentidos ocultos das práticas culturais de matriz africana - muitas delas ainda hoje renegadas pela cultura escolar e pelo conjunto da sociedade - os quais foram, não propriamente esquecidos, mas armazenados na memória corpórea e rítmica de nossos afrodescendentes. Os jovens fizeram ressoar, ao toque do pandeiro e do tambor, práticas ancestrais da capoeira, das rodas de samba... Ou do candomblé? Não sabemos exatamente, pois os alunos demoram muito para se abrir sobre os mistérios dos terreiros e de outras práticas ancestrais. Uma situação que nos fez lembrar, como surgiu o samba no Rio de Janeiro, nos Zungus, também conhecidas como Casas de Angu e batuque, como se chamavam os refúgios de homens e mulheres negras que lá reinventavam práticas culturais comunitárias, duramente reprimidas se praticadas à luz do sol, durante todo o século XIX e

${ }^{11}$ A primeira experiência foi conduzida pela pesquisadora musicista em parceria com a professora de música da Escola de Aplicação, no âmbito da pesquisa Rappers, os novos mensageiros urbanos: a contestação estéticomusical que emancipa e educa (2010-2014); já a segunda foi conduzida por ela e a pesquisadora dançarina de breaking, em parceria com a professora de português, como parte do projeto $O$ ancestral e o contemporâneo nas escolas públicas brasileiras: reconhecimento e afirmação de histórias e culturas urbanas negadas (2015-2018). ${ }^{12} \mathrm{O}$ primeiro era de uma turma da $7^{\mathrm{a}}$ série da Escola de Aplicação da FEUSP e o segundo, da $6^{\mathrm{a}} / 7^{\mathrm{a}}$ série da EMEF Saturnino Pereira, situada na Cidade Tiradentes, zona leste de São Paulo. 
início do século XX. Daí a necessidade de ocultar e disfarçar suas culturas e religiosidade de matriz africana (FARIAS, 2006).

Episódios marcantes como estes, relacionados à musicalidade afro-brasileira em sala de aula, fizeram com que o tambor se tornasse o ponto nodal do trabalho realizado pelas pesquisadoras, em suas dissertações de mestrado. $\mathrm{O}$ instrumento converteu-se em "símbolo organizador" da resistência negra na escola, associada às culturas cultivadas pelos (as) jovens alunos (as) afrodescendentes, nos planos material, sonoro, histórico e subjetivo. Para a pesquisadora dançarina de breaking $^{13}$, representou uma possibilidade de fazer com que os (as) alunos (as) ressignificassem a sonoridade rítmica do tambor ancestral por meio dos passos de breaking ao som das batidas acentuadas do break beat ${ }^{14}$.

Nesta pesquisa, o tambor, quando associado ao termo macumba, emergiu como objeto perturbador, capaz de provocar algumas rupturas de campo no universo escolar e na subjetividade dos sujeitos envolvidos. Mas, ao mesmo tempo, passou a ser o objeto norteador do estudo sobre a trajetória de resistência do negro no Brasil. Seu uso em sala de aula tornouse fundamental para fazer emergir na memória dos afrodescendentes o enraizamento afrodiaspórico das práticas culturais de origem negra no âmbito da escola pública. Ao experimentar a sonoridade do tambor como elemento central de nossas aulas compartilhadas, foi possível ainda ponderar com os alunos que estas práticas têm sido ressignificadas pelas expressões estéticas do hip-hop e do funk. Desencadeou-se, a partir daí toda uma reflexão sobre o papel simbólico desse instrumento para os povos africanos e seus descendentes, que emergiu com força no decorrer da história de resistência cultural das populações da diáspora nas Américas.

É preciso observar que os ecos deste instrumento ressoam ainda hoje nas pick-ups dos DJs por meio dos seus scratchs ${ }^{15}$ e break beats ${ }^{16}$. Osumare (2015) salienta que os tambores afro-cubanos se tornaram um dos instrumentos de percussão favoritos nas primeiras

\footnotetext{
${ }^{13}$ Break beat refere-se ao trecho de uma música, ou os espaços de compasso, normalmente próximos ao refrão, ou que consistem no próprio refrão instrumental, que, para os (as) dançarinos (as) de breaking, representam a batida forte da música. Desse modo, um (a) bom dançarino (a) é aquele (a) que consegue interpretar os beats(as batidas) da música em um ritmo mais percussivo; já para os DJs, o desafio é fazer com que as suas pick-ups ressoem, por meio do break beat, as batidas dos tambores.
}

15 O scratching refere-se a uma decomposição rítmica de algumas métricas por meio da fricção de duas platinas, alternando uma e outra, em pontos diferentes das faixas de um mesmo disco, produzindo um movimento de vai e vem em cada uma das faixas selecionadas.

${ }^{16}$ DJ Kool Herk, um dos ícones do movimento hip-hop nos EUA, por exemplo, só tocava a parte principal dos discos de discos de platina das músicas black norte-americanas e, entre um e outro, impunha o break beat, criando um intervalo de tempo para que o baterista entrasse, alternando-o com o scratching e o carrossel, que eram acompanhados pelo movimento circular do breaking dancing. 
improvisações do breakbeat. Posteriormente, o próprio corpo passou a ser um instrumento percussivo, surgindo danças como tap dance (sapateado norte-americano), criada nos EUA em 1900. O tap dance influenciou, por sua vez, a dança stepping, de caráter mais percussivo, acompanhada de uma mistura de canto, fala, dança e interpretação, que contagiou o público juvenil.

A proposta deste trabalho resultou justamente em um esforço de reflexão a propósito das ressonâncias psíquicas e corpóreas das batidas do tambor ${ }^{17}$ na produção estética dos (as) alunos (as) do $8^{\circ}$ ano do ensino Fundamental II em sala de aula, como uma forma de ressignificar as experiências ancestrais desses jovens com base nas vivências de "letramentos de reexistência" ${ }^{18}$, propiciados pelas práticas da cultura e mídia do Hip-Hop. Uma experiência que se constitui em um modo de romper com o racismo institucional presente nos rituais e ações no âmbito da escola.

Acreditamos que o breaking, ao criar o fundamento power moves ${ }^{19}$, dada a complexidade do movimento e o desafio para a sua consecução - além de fortalecer as juventudes periféricas subvertem igualmente o status quo, ao jogar esta juventude e sua cultura - surgida, paradoxalmente, à margem do sistema e transferida para o centro, irrompendo no coração do Capital.

Ao mesmo tempo, esta juventude hiphopper, ao recriar novas formas de se reconectar à Mãe África, reinventa-se enquanto sujeito. Do mesmo modo que o tambor africano exerceu como veremos com Paul Gilroy (2001) - o papel de "símbolo organizador" da resistência negra no processo diaspórico, a estética do hip-hop faz ecoar em seu breakbeat, as dimensões translocais da música negra da diáspora, conforme salienta o autor. Para ele, dois aspectos se destacam na música afro-americana: o primeiro refere-se à mediação, ao compartilhamento e ao consolo ante o sofrimento vivenciado pelos povos escravizados. O segundo aspecto se deve a uma dramaturgia da recordação de suas origens. Inscritos nos corpos dos negros tornados escravos, esses dois elementos estéticos foram trazidos para as Américas. E colaboraram para

17 O termo tambor compreende o grupo de tambores de família africana utilizados no Brasil em diversas manifestações culturais. No trabalho de campo desta pesquisa, utilizou-se timbas e atabaques por sua relação simbólica com a cultura africana. Timba é um instrumento em forma de ampulheta cilíndrica ou cônica, com uma pele esticada na extremidade maior e uma abertura na extremidade menor; já o atabaque possui um corpo de madeira cilíndrico e afunilado, revestido por pele de animal na extremidade mais larga.

${ }^{18}$ De acordo com a autora, "letramentos de resistência" referem-se à capacidade do Hip-Hop em recombinar o universo do letramento reinventando os usos sociais da linguagem (SOUZA, 2011).

${ }^{19}$ Expressão utilizada por Halifu Osumaré em seu livro: The africanist aesthetic in global hip-hop: power moves. New York: Palgrave Macmillan, 2007. Para a autora, o termo power moves foi empregado para se referir ao processo de internacinalização do hip-hop que foi propiciado, paradoxalmente, pela globalização. 
uma reconfiguração genealógica da memória ancestral de suas tradições culturais a partir do deslocamento geográfico forçado pelo Atlântico.

Analisemos, pois o significado do tambor e suas ressonâncias contemporâneas.

\section{O tambor - o cronótopo moderno}

Gilroy em seu livro O Atlântico Negro (2001) utiliza o termo "símbolo organizador" para se referir ao navio como "um dos primeiros cronótopos ${ }^{20}$ modernos": o modelo representa "um sistema vivo, microcultural e micropolítico em movimento que coloca em circulação, ideias, ativistas, artefatos culturais e políticos" (GILROY, 2001, p. 38).

Neste trabalho, consideramos que o tambor poderia exercer a mesma função, criando um campo microcultural e político capaz de refletir as tensões entre a cultura escolar e as culturas de nossos afrodescendentes. Ao mesmo tempo funcionou como símbolo organizador de nossas proposições em sala de aula, fazendo-nos percorrer a história da diáspora do Atlântico e suas incidências na produção cultural e de resistência dos afrodescendentes nas Américas. Em particular no Brasil, no ir e vir entre o passado e o presente. Foi possível, ao tocar o atabaque e dançar o breaking, reascender neles uma espécie de afromemória rítmica em seus corpos. Além de abrir espaço para uma reflexão sobre as culturas e religiosidade afrobrasileiras, salientou-se o papel do tambor na resistência negra no Brasil Colônia, tanto nos quilombos, quanto em levantes e lutas emancipatórias pela abolição. Um dos temas longamente explorados em sala de aula foi a Revolta dos Malês (REIS, 2003), que se deu em Salvador em 1835. Também foi destacado o papel assumido pelas Comunidades do Tambor (DIAS, 2004), como forma de comunicação e de resistência cultural e política entre os escravizados.

Ponderando sobre os múltiplos aspectos envolvidos na extensa, rica e sofrida história da diáspora do Atlântico Negro, como denominou Gilroy (2001) - a ideia era analisar, como, na atualidade, o hip-hop propõe, de algum modo, um diálogo tensionado entre uma Epistemologia do Sul e a Crítica da Razão Negra. Para tanto, vale-se de uma linguagem musical contundente, acompanhada de videoclipes, que apontam para a afirmação de tudo que tem sido negado aos nossos afrodescendentes. Ao mesmo tempo, valendo-se da ironia, exercitam uma espécie de "pensamento crítico-destrutivo" justamente em relação aos pilares da razão moderna ocidental

20 "Uma unidade de análise para estudar textos de acordo com a frequência e a natureza das categorias temporais e espaciais representadas. [...] O cronótopo é uma ótica para ler textos como raios X das forças em atuação no sistema de cultura da qual elas emanam.” Cf:. Bakhtin, M. M. (1981). The Dialogic Imagination. Edit by Michael Holquist.Translated by Caryl Emerson and Michael Holquist. Austin: University of Texas Press, 1981, p. 426. 
- liberdade, igualdade e fraternidade. Pilares a serem repensados de acordo com uma Epistemologia do Sul (SANTOS, 2017). Já Mbembe (2017) sugere que sejam alargados em direção à construção do "devir-negro" do mundo.

Daí a importância, a nosso ver, de uma pesquisa sobre o significado histórico do tambor no passado e no presente. Urge levantar o véu que oblitera a compreensão do papel fundamental do conhecimento das culturas afrodiaspóricas para a formação de nossas consciências. Além de salientar seu papel nas lutas contra a subalternização das mesmas no campo do conhecimento e das práticas sociais - dentro e fora da escola - de modo a fazer face à demonização de suas culturas.

\section{As batidas do tambor- dos levantes do passado à resistência da juventude negra do presente}

A leitura da obra de Reis (2003), Rebelião escrava no Brasil: a história do levante dos Malês em 1835, permitiu-nos abordar as questões acima apresentadas e contextualizar a Bahia na primeira metade do século XIX. Ele destaca o importante papel dos tambores africanos e reconhece uma dinâmica diaspórica, traduzindo a presença dos laços simbólicos mencionados por Dias (2004) nas Comunidades do Tambor. Tais elos possibilitavam aos escravizados colocar em curso ações e estratégias quotidianas de resistência. Ao tratar especificamente do cenário que envolve o ciclo do açúcar e a Revolta dos Malês, Reis (2003, p. 23) retrata a diversidade de origem dos vários povos ${ }^{21}$ que revelavam diferentes cores entre os nascidos no Brasil, em oposição ao olhar homogeneizante sobre os povos africanos trazidos pelo tráfico. Os africanos se distinguiam, segundo o autor, não por cores, mas por "nações". O território baiano apresentava uma grande heterogeneidade de práticas cotidianas. No embate entre brancos e negros, a música negra surgiu em um cenário de grande diversidade cultural, como fator de aglutinação e de união política e simbólica entre os escravizados.

As distintas formas de expressão rítmica dos negros no Brasil surgiram dos desdobramentos e conjunções histórico-sociais peculiares às quais foram submetidas às populações afrodescendentes. Ponderando sobre as inúmeras influências e repercussões que a batida do tambor fez ressoar nas diferentes regiões de nosso país, buscamos nesta exposição fazer apenas um recorte dos aspectos históricos e simbólicos que envolvem o tambor africano,

${ }^{21}$ Reis faz um minucioso levantamento dessas diferentes situações etnográficas na Bahia. Monteiro (2010) nos informa dados semelhantes no Rio de Janeiro no mesmo período, em seu artigo Aspectos da música no Brasil na primeira metade do século XIX. 
a partir de dados historiográficos apresentados por Reis (2003), inspirados pela ideia de solidariedade negra de Gilroy (2001) e de Schafer (2011). Reis (2003) coloca a música em uma perspectiva de análise que revela sua importância simbólica para os africanos, e não apenas como mais um elemento de uma determinada expressão cultural de caráter polissêmico. A sonoridade dos tambores africanos e as manifestações culturais que aconteciam ao ritmo desses instrumentos eram indícios de uma identificação étnica, antes de tudo. Segundo o autor, o uso que os africanos faziam da música em seu quotidiano, era no sentido de conservar os costumes originários da vida na África.

Ao estudarmos esta obra com os alunos, ao mesmo tempo em que lhes apresentávamos as diversas sonoridades rítmicas que ressoavam das batidas em diferentes formas de tambores (atabaques, tumbas, etc), foi possível identificar neste passado a origem do preconceito em relação a estes instrumentos. Pois, o autor relata inúmeras publicações dos jornais da época que repudiavam o "alarido" dos tambores, palmas e cantos dos escravizados, que estava aterrorizando a elite baiana, receosa de que junto com estes ruídos, pudessem se alastrar levantes e rebeliões com a que ocorrera no Haiti, em 1804 e que ocorreu efetivamente em 1835, na revolta dos Malês.

Este foi o esteio para a construção do preconceito direcionado aos tambores, bastante útil para catalisar os temores da população branca ante a possibilidade da insurgência de novas revoltas negras. Schafer (2011) acrescenta a este sentido de continuidade de si - mantido pelos tambores entre os escravizados - outra instigante informação, acerca da paisagem sonora africana no Brasil, relacionada à sofisticação dos sistemas de comunicação negros, chamados de tambores telegráficos da África, referindo-se ao exemplo mencionado por Carrington (1969):

[...] (são utilizados dois tambores alto e grave) e, embora algumas vezes se empreguem diferentes tipos de batida, o código mais frequente é estritamente binário. Poder-se-ia supor que essa limitação tornaria impossível enviar mensagens complexas, mas não é o que acontece. Embora a ambiguidade possa existir, a redundância é introduzida para clarificar a mensagem. Por exemplo, se o sinal para lua e frango é idêntico, consistindo em duas batidas no tambor agudo (como é o caso da tribo Lokele, no Congo), o significado torna-se claro pela adição de uma frase explicativa para cada palavra (CARRINGTON, 1969 apud SCHAFER, 2011, p. 233).

Os mais variados sistemas de comunicação acústica tinham como objetivo impelir a voz humana o mais longe possível. Os tambores falantes da África conservam em suas características sonoras o contorno e o impulso, podendo ser ouvidos cerca de sessenta milhas 
de distância em uma noite silenciosa. Numa fusão de ritmo e melodia é “o mais elegante sistema de comunicação jamais criado" (SCHAFER, 2011, p. 233).

\section{As origens do preconceito aos ritmos e instrumentos africanos - uma demonização historicamente construída}

Conforme fomos avançando na pesquisa junto aos (as) alunos (as) e nas leituras sobre a educação das crianças e jovens nos terreiros (CAPUTO, 2012), foi-se percebendo que as falas dos (as) alunos (as) que identificavam nos instrumentos e rituais afro-brasileiros - como, por exemplo, nas rodas de capoeira - eram repletas de ambiguidades. Eram frases ditas esparsamente, às vezes, claudicantes, que demonstravam conhecimento dos rituais de candomblé, ao mesmo tempo em que pareciam temê-los ou repudiá-los. Claro que havia a interpretação das religiões pentecostais interferindo. Mas parecia haver algo muito próximo de uma estratégia de sobrevivência na escola, bem semelhante ao modo como os escravizados e libertos fizeram para preservar sua cultura. Quer dizer, realizavam seus rituais na intimidade do grupo de pertença, mas conferiam aos mesmos uma nova roupagem frente ao mundo branco e cristão. Descortinava-se, assim, um cenário para as pesquisadoras e professora, no qual os afrodescendentes eram e continuam sendo de algum modo obrigados a omitir sua religião e a disfarçar sua fé para não serem mais perseguidos.

Uma observação importante feita pela pesquisadora e musicista é que os sons proscritos, assim chamados por Schafer (1997), tinham enorme ressonância simbólica e cultural. Uma ideia semelhante encontrada na obra de Reis (2003), que identificou nos tambores africanos e nos batuques um tipo diferente de rebelião, uma vez que estes comunicavam que os africanos e seus descendentes não deixariam escravizar suas mentes.

A respeito da palavra macumba, Caputo (2012) esclarece que, de acordo com a definição de Berkenbrock (1998), este termo refere-se à religião afro-brasileira surgida no Rio de Janeiro, que é oriunda da tradição religiosa banta. Termo que é utilizado por aqueles que a praticam para se referir às práticas das religiões afro-brasileiras de um modo geral, e que só tem um sentido pejorativo para as pessoas que não pertencem ao candomblé.

A esse respeito, seria interessante observar as reações opostas de duas alunas acerca dos ritmos africanos, associados por ambas à macumba. Embora fossem alunas de uma mesma classe, da mesma faixa etária e que viviam muito próximas uma da outra, enquanto uma demonstrara apreensão com o tema, a outra se pôs a dançar. O que talvez sugerisse maior ou menor intimidade com os rituais e ritmos africanos. 
A partir destes dois recortes de nossa pesquisa de campo, um, demonstrando os ecos ancestrais eliciados pelo toque do tambor, e outro relativo ao emprego da palavra macumba para se referir ao instrumento, retomemos o debate sobre uma epistemologia do sul afrocentrada.

\section{Em direção a uma epistemologia do sul afro-brasileira}

Partimos inicialmente dos estudos e pesquisas realizados por Santos, cujas ideias centrais foram sintetizadas em seu livro, Renovar a teoria crítica e reinventar a emancipação social (SANTOS, 2017), onde ressalta a importância de se expandir as experiências e conhecimentos pressupostos pela razão ocidental, ou "razão indolente" (SANTOS, 2000). A razão ocidental foi assim designada pelo autor justamente pelo fato de suprimir ou negar as necessidades e os modos de viver e de pensar de povos e países do hemisfério sul, ou mesmo dos grupos sociais que, embora pertençam a países do hemisfério norte, encontram-se igualmente subalternizados. O autor está interessado em uma epistemologia engajada socialmente, que resulte em ações capazes de romper com a racionalidade ocidental presente em nossa formação e que tende a se enraizar institucionalmente.

Para tanto, seria necessário um duplo esforço: trabalhar algumas categorias e conceitos hegemônicos de forma contra hegemônica. Ou, de acordo com a expressão empregada pelo autor, na perspectiva das "semânticas legítimas da convivência política e social", como: "a legalidade, a democracia e os direitos humanos. [E, ao mesmo tempo, tentar] perceber, nas culturas e formas políticas marginalizadas pela modernidade ocidental, indícios, sementes e embriões do novo" (SANTOS, 2017, p. 11). Um processo que demanda, segundo o autor, "a paciência infinita da utopia" (SANTOS, 2017, p. $11)$.

Em outro livro, A crítica da razão indolente: contra o desperdício da experiência, Santos (2000) defende que uma orientação emancipatória para a ciência deve se opor ao colonialismo da ciência moderna, uma vez que esta é pautada pela ignorância e a incapacidade de conceber o outro a não ser como objeto. Considera que estamos experimentando uma verdadeira transição paradigmática da ciência, cuja opção epistemológica deve se pautar justamente pelo conhecimento emancipatório, com base na solidariedade:

A solidariedade é o conhecimento obtido no processo, sempre inacabado, de nos tornarmos capazes de reciprocidade através da construção e do reconhecimento da intersubjetividade. A ênfase na solidariedade converte a comunidade no campo privilegiado do conhecimento emancipatório" (SANTOS, 2000, p. 81). 
De acordo com Santos (2017), precisamos de um novo conhecimento com base em uma nova epistemologia, uma vez que o conhecimento é muito mais amplo do que a "compreensão ocidental do mundo" (SANTOS, 2017, p. 20). No convívio com tantas realidades distintas ${ }^{22}$, chegou à conclusão de que "não há ciência pura, há um contato cultural de produção de ciência" (SANTOS, 2017, p. 23). Portanto, sugere uma epistemologia do Sul em oposição à epistemologia positivista que sustenta ser a ciência independente da cultura. E que seja capaz de romper com os cinco sentidos do monoculturalismo ocidental: do saber e do rigor científicos, do tempo linear, da naturalização das diferenças, da escala dominante e do produtivismo capitalista.

Gomes (2017) por sua vez, em seu livro O Movimento Negro educador - saberes construídos nas lutas por emancipação, salienta o papel fundamental exercido pelo Movimento Negro Unificado (MNU) para a conquista dos direitos civis dos afrodescendentes no Brasil. A autora explicita o racismo à brasileira, construído com base no mito da democracia racial, conforme amplamente explorado por Munanga (2004, 2009) e Munanga e Gomes (2006). Um mito que penetrou nas entranhas do tecido social brasileiro e na construção da própria subjetividade dos afro-brasileiros. Mas que tem sido desmascarado e desmontado, graças ao conhecimento propiciado pelo acúmulo de experiências dos movimentos e culturas negras veiculados pelo MNU.

Gomes (2017) considera, ainda, que os projetos educativos desenvolvidos pelo movimento negro sejam eminentemente emancipatórios, uma vez que passam pela valorização da história, das culturas e saberes das comunidades negras, com vistas à transformação social e cultural do conjunto da sociedade. Sustenta que o movimento negro tenha contribuído para o que Boaventura Santos considera ser uma "sociologia das ausências”, ou seja, a necessidade de se construir as bases sócio-políticas e epistemológicas para o reconhecimento da diversidade étnico-racial e religiosa no país. Bem como para uma "sociologia das emergências", capaz de romper com a estrutura ocidental, eurocêntrica e estadunidense, diríamos nós, da escola, da universidade e do saber científico.

Considerando a complexidade deste debate, nossa ideia é contribuir para fazer avançar a discussão a respeito da epistemologia do Sul, bem como a crítica dirigida por Santos (2000, 2017) ao monoculturalismo ocidental, tomando em consideração os saberes de nossos afrodescendentes. Inspirando-nos nas ideias que Mbembe expõe em seu livro, Crítica da Razão Negra (MBEMBE, 2017), a ideia é promover a descolonização das mentes e corpos negros, subalternizados pela herança do escravismo e da colonização euro-americana da África

${ }^{22}$ Para romper a tradicional divisão entre pesquisadores do norte que usualmente pesquisam os países do hemisfério sul e os do sul, que tendem a pesquisar sua própria realidade local, propôs um projeto que se chamou "Reinventar a emancipação social a partir do Sul', reunindo 60 pesquisadores de seis países: Portugal, Colômbia, Brasil, África do Sul, Índia e Moçambique. 
e das Américas. Uma herança que produziu a "reativação da lógica das raças", convertendo o "paradigma negro" no "paradigma de uma humanidade subalterna", cuja consequência foi o "racismo institucional". Mbembe (2017) defende a descolonização do modo de pensar europeu com base no respeito ao outro, acompanhada de uma ampla concepção de justiça e de responsabilidade social. Salienta que, para sua efetivação, seria necessária a reparação do racismo infligido aos povos negros.

No entanto, é preciso observar, como bem salienta Jesus (2018), que o racismo à brasileira não se efetivou por meio de uma discriminação legal oficializada pelo Estado, mas, com base na suposta inferioridade do negro, foram instituídas "práticas de hierarquização racial" enquanto "práticas sociais", que foram naturalizadas de modo a garantir a "produção e reprodução das discriminações e desigualdade” étnico raciais (JESUS, 2018, p. 4).

Mbembe (2017) salienta que, a despeito de todas as ameaças à cultura negra produzida pela diáspora, sua experiência em diferentes universidades, o fez habitar diversos mundos e construir um pensamento de circulação e de travessia, anunciando, nesse sentido, o "devir negro" do mundo. Não no sentido de opor uma nova universalidade à razão ocidental, mas no sentido de construir um pensamento capaz de se "reinventar, atualizar e reatualizar nossa capacidade de reinvenção", sempre dialogando com o diferente, para quem "o outro não é mais do que a diferença e o semelhante reunidos" (MBEMBE, 2017, p. 297).

No que se refere aos aspectos simbólicos e subjetivos presentes nas músicas de origem africana, este estudo traz algumas contribuições de Gilroy (2001) para o debate sobre os processos culturais, sociais, políticos que ocorreram nas Américas a partir da experiência da diáspora do Atlântico, ressaltando a importância de leituras sob novos ângulos. O autor ressalta a importância de os negros serem "percebidos como agentes, como pessoas com capacidades cognitivas e mesmo com uma história intelectual" e cultural significativa (GILROY, 2001, p. 40). O aprofundamento de tais dimensões exigiria uma atenção especial aos processos culturais relativos às qualidades polifônicas do tambor africano. Desta perspectiva, procurou-se analisar as manifestações estéticas, políticas e subjetivas que ocorreram em torno deste instrumento no passado e suas incidências no presente.

Com preocupação semelhante, procuramos identificar os "atributos negados [aos negros] pelo racismo moderno" com base em "concepções racialmente exclusivas de identidade nacional, da qual os negros foram excluídos, ora como não humanos, ora como não cidadãos" (GILROY, 2001, p. 41).

$\mathrm{O}$ autor identifica dimensões significativas translocais, que promovem a junção de dois aspectos presentes no cerne da música negra da diáspora. $\mathrm{O}$ primeiro refere-se à mediação, ao 
compartilhamento e ao consolo ante o sofrimento vivenciado pelos povos escravizados. $\mathrm{O}$ segundo aspecto se deve a uma dramaturgia da recordação de suas origens africanas. Inscritos nos corpos dos negros tornados escravos, esses dois elementos estéticos foram trazidos para as Américas, colaborando para uma reconfiguração genealógica da memória ancestral de suas tradições culturais a partir do deslocamento geográfico forçado pelo Atlântico.

Não se pode deixar de mencionar que os tambores e os batuques que ecoam no Brasil desde os tempos da colônia têm uma história própria, marcando presença na cultura banto, cuja memória foi trazida pelos povos oriundos de Angola, do Congo e de Moçambique, que foram arrancados de suas terras e comercializados pelo tráfico em diferentes regiões do Brasil.

No entanto, a despeito desta riqueza estética herdada da diáspora, houve momentos da pesquisa de campo na escola em que o termo "macumba" foi associado ao tambor africano, cuja sonoridade gerou os mais diversos sentimentos de temor e respeito, dor e resignação, que impediam a aproximação dos alunos do instrumento. Atentas ao que emergia entre os alunos (as), mas também ao caráter eurocêntrico da cultura escolar, procurou-se considerar as ambiguidades de sentido inerentes ao próprio termo, ao duplo sentido tão comum na tradição africana, empregado como estratégia de resistência à escravidão nas Américas, presente em diversos estilos musicais afro-americanos, como bem salienta Smith (2015). E que talvez estivesse emergindo toda essa dubiedade de sentidos atribuída ao tambor em nossas atividades em sala de aula.

\section{Considerações finais}

Nossa ideia era propiciar uma formação voltada à emancipação da consciência de nossos jovens afrodescendentes, que fosse além da apropriação do instrumental técnico-científico e que proporcionasse um aprendizado aberto à elaboração da história e, como dissera o filósofo Theodor Adorno (2010), ao contato com "o outro não idêntico", portanto, aberto à diversidade. De outro lado, foi se evidenciando que a construção de um conhecimento engajado dependia do reconhecimento dos povos historicamente prejudicados, de suas culturas e saberes, que foram apropriados indevidamente pelo Ocidente, como sustentam os pensadores afrocêntricos (ASANTE, 2009; MBEMBE, 2017). Além disso, é preciso observar que as origens dos inúmeros povos oriundos de diferentes regiões da África foram apagadas quando não destruídas - restando à historiografia e à antropologia engajadas, pesquisar os indícios e traços que restaram de suas origens. ${ }^{23}$

${ }^{23}$ Prandi (2000) sustenta, por exemplo, que, devido à "destruição no Brasil das linhagens da família africana”, grande parte da ancestralidade de seus membros não pode ser estabelecida, a não ser por meio da "concepção mítica das linhagens". Esclarece, ainda, que a chegada tardia no séc. XIX de etnias sudanesas na Bahia urbana 
Santos $(2000,2017)$ está interessado em estimular ações rebeldes e contribuir para a construção de subjetividades rebeldes, que sejam capazes de romper com a racionalidade ocidental, impregnando toda a nossa formação. O trabalho empreendido por nosso grupo de pesquisa em sala de aula - ao recorrermos à musicalidade negra diaspórica que acompanhou os levantes dos escravizados no passado e que faz parte da resistência de nossos jovens afrodescendentes no presente - gerou justamente as condições para pensarmos com os professores em estratégias de ensino que estimulassem a construção de subjetividades e ações rebeldes entre os alunos.

Nosso trabalho opôs-se, em particular, a um dos sentidos apontados pelo autor relativo à monocultura ocidental. Ou seja, à concepção de que o saber rigoroso consistiria no saber científico, o qual, desde a expansão do domínio europeu no mundo, confundiu-se com a ciência ocidental. Ignoramse as inúmeras práticas sociais envolvidas nos conhecimentos populares, camponeses e urbanos, nos conhecimentos indígenas e, diríamos nós, também do conhecimento das culturas de matriz africana, resultantes da diáspora negra do Atlântico para as Américas.

De outro lado, o racismo institucional do qual fala Mbembe (2017), presente no espaço escolar, ao ser confrontado com as práticas, danças e ritmos suscitados pelos instrumentos de matriz africana - foi de algum modo rompido por dentro. Permitiu tanto a emergência de lembranças longínquas de uma experiência comunitária, como o samba de roda - no imaginário dos professores e dos alunos - como produziu uma escuta e um olhar atentos ao matizado híbrido da cultura brasileira. Nosso trabalho em sala de aula, envolvendo a dança breaking uma das expressões estéticas do movimento hip-hop - e a experimentação musical com instrumentos de percussão afro-brasileiros. A parceria com a professora de português, que conhecia muito bem os ritmos de matriz africana, foi fundamental para a construção de um saber afrocentrado. Portanto, culturalmente relevante para os alunos. O tambor assumiu um papel verdadeiramente catalizador das experiências de ressignificação da ancestralidade africana daqueles alunos. Despertou uma espécie de afromemória que, ao mesmo tempo, pode ser reinventada por meio da dança breaking e das bases de funk recriadas com instrumentos de percussão.

permitiu que velhos africanos fossem reconhecidos por sua etnia, ao contrário dos nascidos no Brasil há mais tempo, que tiveram suas origens apagadas. Ressalta que os Nagôs, assim chamados no Brasil, eram remanescentes das nações iorubás e reuniam muitas etnias, como as de "Ilorin, Ijexá, Abeokutá (egbás), Lagos, Ketu e Ibadan e Ifé, sendo que os provenientes da região central da iorubalândia (Oyó,Ilorin, Ijaxá) eram quase todos malês ou muçulmanos". Na verdade, os termos banto e sudanês englobam diferentes nações africanas, sendo que os primeiros sustentaram as atividades agrícola e mineradora e os segundos - fazendo parte destes, os nagôs-iorubás - exerceram atividades urbanas, acompanhando momentos históricos distintos do tráfico. Muitas informações dessas diferentes linhagens africanas, cuja memória se tentou apagar, reaparecem em letras de músicas de capoeira, candomblé e outros rituais afro" (PRANDI, 2000, p. 56). 
Queremos dizer com isto que faz parte desta construção, repensarmos o ensino e a educação de um modo geral, como um processo de descolonização de mentes e corpos. É necessário, inclusive, rever as regras institucionais e o próprio ritual e cultura escolar com base nas culturas e saberes populares que foram banidos da escola. Dar ênfase às culturas jovens urbanas é uma forma de contribuir para a construção de um currículo capaz de dialogar mais diretamente com as necessidades subjetivas e de formação intelectual da juventude periférica.

\section{REFERÊNCIAS}

ADORNO, T. W. Educação e emancipação. São Paulo: Paz e Terra, 2010.

AMARAL, M. et al. Culturas juvenis X cultura escolar: como repensar as noções de tradição e autoridade no âmbito da educação?. Projeto de Pesquisa apresentado ao Programa "Melhoria do Ensino Público", FAPESP, São Paulo, 2006.

AMARAL, M. et al. Rappers, os novos mensageiros urbanos da diáspora afro-brasileira na periferia de São Paulo: a contestação estético-musical que emancipa e educa. Projeto de Pesquisa apresentado ao Programa de "Políticas Públicas", FAPESP, São Paulo, 2010.

AMARAL, M. et al. $\mathbf{O}$ ancestral e o contemporâneo nas escolas públicas brasileiras: reconhecimento e afirmação de histórias e culturas urbanas negadas. Projeto de pesquisa apresentado ao Programa de "Políticas Públicas", FAPESP, São Paulo, 2015.

ASANTE, M. K. Afrocentricidade: notas sobre uma posição disciplinar. In: NASCIMENTO, E. L. (Org.). Afrocentricidade: uma abordagem epistemológica inovadora. São Paulo: Selo Negro, 2009, p. 93-110.

BENJAMIN, W. A obra de arte na época de suas técnicas de reprodução. In: BENJAMIN, W. et al. Textos escolhidos. 2. ed. São Paulo: Abril Cultural, 1980. p. 3-28. (Os Pensadores, 63).

BERKENBROCK, V. J. A experiência dos orixás: um estudo sobre a experiência religiosa do candomblé. Rio de Janeiro: Vozes, 1998.

BÉTHUNE, C. Le rap: une esthétique hors la loi. Paris: Autrement, 2003.

CAPUTO, S. G. Educação nos terreiros e como a escola se relaciona com crianças de candomblé. Rio de Janeiro: Pallas, 2012.

CARRINGTON, J. F. Talking drums of Africa. Nem York: Negro Universities Press, 1969.

DIAS, P. Comunidades do tambor. In: VVVA. Textos do Brasil. Brasília: Ministério das Relações Exteriores, 2004. n. 11. 
DIAS, C. C. Por uma pedagogia hip-hop: o uso da linguagem do corpo e do movimento para a construção da identidade negra e periférica. Dissertação (Mestrado em Educação) Faculdade de Educação, Universidade de São Paulo, SP, 2018.

FARIAS, J. B. Cidades negras: africanos, crioulos e espaços urbanos no Brasil escravista do século XIX. São Paulo: Alameda, 2006.

GATTI, L. Constelações: crítica e verdade em Benjamin e Adorno. São Paulo: Loyola, 2009. 355 p. (Coleção Filosofia, 76).

GILROY, P. O Atlântico negro: modernidade e dupla consciência. São Paulo: Editora 34; Rio de Janeiro: UCAM - Centro de Estudos Afro-Asiáticos, 2001.

HERRMANN, F. Andaimes do real: o método da psicanálise. São Paulo: Casa do Psicólogo. 2001.

HONNETH, A. Luta por reconhecimento: a gramática moral dos conflitos sociais. São Paulo: Editora 34, 2003.

JESUS, R. E. Mecanismos eficientes na produção do fracasso escolar de jovens negros: estereótipos, silenciamento e invisibilização. Educação em Revista, Belo Horizonte, n. 34, p. 1-18, 2018. Disponível em: http://dx.doi.org/10.1590/0102-4698167901. Acesso em: 26 jun. 2018 .

LODUCA, M. T. Música negra na escola: um estudo sobre a ressonância dos tambores nas relações intersubjetivas. Dissertação (Mestrado em Educação) - Faculdade de Educação, universidade de São Paulo, SP, 2018.

MBEMBE, J. A. Crítica da razão negra. Lisboa: Antígona, 2017.

MONTEIRO, M. Aspectos da música no Brasil na primeira metade do século XIX. In: MORAES, J. G. V.; SALIBA, E. T. (Org.). História e música no Brasil. São Paulo: Alameda, 2010, p. 79-118.

MUNANGA, K. Rediscutindo a mestiçagem no Brasil: identidade nacional versus identidade negra. Belo Horizonte: Autêntica, 2004.

MUNANGA, K.; GOMES, N. L. Para entender o negro no Brasil de hoje: história, realidades, problemas e caminhos. São Paulo: Global / Ação Educativa, 2006.

MUNANGA, K. Prefácio. In: CARONE, I.; BENTO, M. A. S. Psicologia social do racismo: estudos sobre branquitude e branqueamento no Brasil. Rio de Janeiro: Vozes, 2009. p. 9-11.

OSUMARE, H. The africanist aesthetic in global hip-hop: power moves. New York: Palgrave Macmillan, 2007.

PRANDI, R. De africano a afro-brasileiro, etnia, identidade, religião. Revista USP, São Paulo, n. 46, p. 52-65, 2000. 
REIS, J. J. Rebelião escrava no Brasil: a história do levante dos Malês em 1835. Ed. rev. ampl. São Paulo: Companhia das Letras, 2003.

SANTOS, B. S. A crítica da razão indolente: contra o desperdício da experiência. 2. ed. São Paulo: Cortez, 2000. 415 p.

SANTOS, B. S. Renovar a teoria crítica e reinventar a emancipação social. São Paulo: Boi tempo, 126 p. 2017.

SCHAFER, R. M. O ouvido pensante. São Paulo: UNESP, 1997.

SCHAFER, R. M. A afinação do mundo: uma exploração pioneira pela história passada e pelo atual estado do mais negligenciado aspecto do nosso ambiente: a paisagem sonora. 2. ed. São Paulo: Unesp, 2011.

SMITH, W. E. O hip hop e suas conexões com a diáspora africana. In: Autor; Carril, L. O hip hop e as diásporas africanas na modernidade - uma discussão contemporânea sobre cultura e educação. São Paulo: Alameda-FAPESP, 2015, p.93-105.

SOUZA, Ana Lúcia Silva. Letramentos da reexistência: poesia, grafite, música, dança: HipHop. São Paulo: Parábola Editorial, 2011.

\section{Como citar este artigo:}

AMARAL, Mônica Guimarães Teixeira.; DIAS, Cristiane Correia.; LODUCA, Maria Teresa. Culturas urbanas e resistência da juventude negra: ressonâncias do tambor nas escolas da periferia de São Paulo. Revista Ibero-Americana de Estudos em Educação, Araraquara, v. 14, n. 3, p. 1081-1099, jul./set., 2019. e-ISSN: 1982-5587. DOI: 10.21723/riaee.v14i3.11996

Data de Submissão: $17 / 12 / 18$

Revisões requeridas: $20 / 01 / 19$

Aceite em: 30/03/19

Publicado em: 10/05/19 